\title{
The CAVEheAT project: climate change, thermal niche and conservation of subterranean biodiversity
}

\author{
David Fernandez", Andrés Millán§, Valeria Rizzol, Jordi Comasף, Enric Lleopardף, Josep Pastor", \\ Susana Pallarés ${ }^{\ddagger}$, Pedro Abellán\#, Michele Spada“, David T. Bilton“, Ignacio Ribera” \\ ‡ University of Castilla-La Mancha, Toledo, Spain \\ $\S$ University of Murcia, Murcia, Spain \\ | Unaffiliated, Roma, Italy \\ If Museu de Ciències Naturals, Barcelona, Spain \\ \# Universidad de Sevilla, Sevilla, Spain \\ a Barcelona Supercomputing Center, Barcelona, Spain \\ "University of Plymouth, Plymouth, United Kingdom \\ »Instituto de Biología Evolutiva, Barcelona, Spain
}

Corresponding author: David Fernandez (david.sfernandez@uclm.es)

Received: 26 Sep 2018| Published: 02 Oct 2018

Citation: Fernandez D, Millán A, Rizzo V, Comas J, Lleopard E, Pastor J, Pallarés S, Abellán P, Spada M, Bilton

D, Ribera I (2018) The CAVEheAT project: climate change, thermal niche and conservation of subterranean biodiversity. ARPHA Conference Abstracts 1: e30105. https://doi.org/10.3897/aca.1.e30105

\begin{abstract}
One of the main challenges in disciplines such as ecology, biogeography, conservation and evolutionary biology is to understand and predict how species will respond to environmental changes, especially within a climate change context. We focus on the deep subterranean environment to minimize uncertainties in predictions, because it is one of the few ecosystems in nature whose environmental conditions are as homogeneous as those in the laboratory and their species cannot accommodate to changing conditions by behavioural plasticity, dispersal or microhabitat use (i.e., their only possibility to cope with climate change is to persist in situ). The hypotheses established for this project are based on the exciting results obtained in some of our previous studies, in which, we found that different subterranean beetle species living under different environmental conditions have identical/similar narrow thermal tolerance ranges, suggesting a lack of evolutionary adjustment to ambient temperature for these species. This could be due to the loss of
\end{abstract}


some of the physiological mechanisms related to thermal tolerance, with a likely high metabolic cost, in a stable environment but with severe resource restrictions. However, the question that remains is to what extent this surprising narrow and homogeneous thermal niche is common for the whole subterranean biodiversity, and how this issue could determine the fate of subterranean biodiversity to climate change. In this project, we are testing for the generality of these exciting previous findings by studying the thermal niche (species acclimation abilities and thermal tolerances) of different lineages of cave beetles with different degrees of specialization to subterranean environments and from different geographical areas (Pyrenees and Cantabrian Mountains) (Suppl. material 1).

\section{Presenting author}

David Sánchez-Fernández

\section{Presented at}

24th International Conference on Subterranean Biology. August 2018.University of Aveiro (Portugal)

\section{Acknowledgements}

This project is funded by the Spanish Ministry of Economy and Competitiveness (CGL2016-76995-P).

\section{Supplementary material}

\section{Suppl. material 1: The CAVEheATproject: climate change, thermal niche and conservation of subterranean biodiversity doi}

Authors: Sánchez-Fernández, David; Millán, Andrés; Rizzo, Valeria; Comas, Jordi; Lleopart, Enric; Pastor Josep; Pallarés, Susana; Abellán, Pedro; Spada, Michele; Bilton, David T.; Ribera, Ignacio

Data type: project

Filename: CAVEheAT_presentacion.pdf - Download file (1.25 MB) 